\title{
A novel evaluation system to monitor bone formation and $\beta$-tricalcium phosphate resorption in opening wedge high tibial osteotomy
}

\author{
T. Tanaka $\cdot$ Y. Kumagae $\cdot$ M. Chazono $\cdot$ \\ S. Kitasato • A. Kakuta • K. Marumo
}

Received: 14 June 2013/ Accepted: 22 January 2014/Published online: 5 February 2014

(c) The Author(s) 2014. This article is published with open access at Springerlink.com

\begin{abstract}
Purpose The aim of this study was to establish an evaluation system to monitor bone formation and beta-tricalcium phosphate (TCP) resorption in opening high tibial osteotomy (HTO).

Methods From 2003 to 2005, opening HTO was performed in 36 patients using a Puddu plate and $\beta$-TCP blocks with 60 and $75 \%$ porosity. Thirty-one patients were used for evaluation. All patients underwent CT examination at 2 weeks and 6 years. The CT image data were divided into three areas, and CT values of each area were analysed using the imaging software, Osirix.

Results CT image analysis at 2 weeks showed that the mean CT-attenuation values (in Hounsfield units) of the implanted area with $\beta$-TCP of $60 \%$ porosity, the implanted area with $\beta$-TCP of $75 \%$ porosity, and cancellous bone were, 1,694.0 \pm 94.2, 1,010.9 \pm 81.1 , and $178.0 \pm$ 45.1 , respectively. Six years after surgery, these values were $574.1 \pm 273.5,168.8 \pm 75.1$, and $174.9 \pm 69.3$, respectively.

Conclusion $\beta$-TCP with $75 \%$ porosity was completely resorbed and replaced by bone. $\beta$-TCP with $60 \%$ porosity was resorbed, but approximately $1 / 3$ still remained even 6 years after surgery. The imaging software, Osirix, enabled scanning of the whole area to measure CT values.
\end{abstract}

T. Tanaka $(\bowtie) \cdot$ Y. Kumagae · M. Chazono

Department of Orthopaedic Surgery, NHO Utsunomiya

National Hospital, 2160 Shimo-Okamoto, Utsunomiya,

Tochigi 329-1193, Japan

e-mail: tanakat@e-utunomiya.hosp.go.jp

S. Kitasato · A. Kakuta $\cdot$ K. Marumo

Department of Orthopaedic Surgery, Jikei University School

of Medicine, Tokyo 105-8461, Japan
This system is the first to quantitatively evaluate $\beta$-TCP resorption and bone formation in opening HTO.

Level of evidence Laboratory studies.

Keywords $\beta$-TCP · Opening wedge HTO - Osirix · Bone formation

\section{Introduction}

Lateral closed wedge high tibial osteotomy (HTO) described by Jackson and Waugh [7] and Coventry [3] is an established technique to treat osteoarthritis of the medial compartment and varus deformity. This technique has gradually given way to medial opening wedge osteotomy. The advantages of a medial opening wedge osteotomy compared with a lateral closing wedge osteotomy include easier technique, achievement of more predictable correction [5], maintenance of bone stock, correction of the deformity close to its origin, and avoidance of the peroneal nerve, and, proximal tibiofibular joint. However, a suitable material to fill the opened defect in the medial opening procedure has not been identified. Although autogenous bone is the preferred graft material for filling bone defects [21], autogenous bone grafting has the disadvantages of comorbidity at the donor site. Allografts have commonly been used as substitutes for autogenous bone grafts; significant problems associated with allografts include a low bone fusion rate and disease transmission [2, 8]. Recently, bone substitute materials have been advocated as alternatives to autografts and allografts. Hydroxyapatite is widely used as a bone substitute because of its excellent biocompatibility and osteoconductive properties [9, 14]. Although it biodegrades slowly and there is no progressive bone formation during the bone repair [6]. Koshino et al. [10] 
reported good long-term results after opening HTO using hydroxyapatite as a bone filler. If, however, severe varus or valgus knee deformities were to occur, fixing a component in the tibia during total knee arthroplasty might be difficult. In contrast, most implanted porous $\beta$-tricalcium phosphate (TCP) can be resorbed within a few years [17]. In previous studies, we used $\beta$-TCP with $75 \%$ porosity, but this has a compressive strength of only $3 \mathrm{MPa}$, which is inadequate for weight-bearing sites until bone incorporation occurs. Thus, we recently developed a wedge-shaped $\beta$-TCP block with $60 \%$ porosity for opening HTO. This $\beta$-TCP has a compressive strength of $22 \mathrm{MPa}$, which is approximately sevenfold greater than $\beta$-TCP with $75 \%$ porosity. We previously reported the clinical results of bone formation and resorption of $\beta$-TCP using $\beta$-TCP blocks with 75 and $60 \%$ porosity at 33 months [18]. During opening HTO, the opened defect was fixed with a Puddu plate, after which $\beta$-TCP with $75 \%$ porosity was used to fill the cancellous bone defect. On the medial cortical bone side, however, a wedge-shaped $\beta$-TCP block with $60 \%$ porosity was implanted in front of and at the back of the plate. The use of a $\beta$-TCP block with $60 \%$ porosity avoided autogenous bone grafting and shortened the surgical time. The decreased porosity reduced pore interconnection, suggesting a longer period for $\beta$-TCP resorption. In that study, radiographic examination showed that $\beta$-TCP with $75 \%$ porosity was almost completely resorbed, but some $\beta$-TCP with $60 \%$ porosity remained. Other reports also evaluated $\beta$-TCP resorption in opening HTO using plain X-rays [1, 4, $11,16,19]$. To our knowledge, no radiological rating system to monitor remodelling of $\beta$-TCP using CT images has been reported. The aim of this study was to establish a novel evaluation system to monitor bone formation and $\beta$-TCP resorption in opening HTO.

\section{Materials and methods}

\section{Preparation of $\beta$-TCP}

The $\beta$-TCP block used in this study was highly pure and provided by Olympus Biomaterials Co. Ltd., Tokyo, Japan. $\beta$-TCP was synthesized using a mechanochemical method (wet milling). Briefly, $\mathrm{CaHPO}_{4} / \mathrm{H}_{2} \mathrm{O}$ and $\mathrm{CaCO}_{3}$ at a molar ratio of 2:1 were mixed into a slurry with pure water and particles of zirconium in a pot mill for $24 \mathrm{~h}$ and dried at $80^{\circ} \mathrm{C}$. Calcium-deficient hydroxyapatite was converted to $\beta$-TCP by calcination at $750{ }^{\circ} \mathrm{C}$ for $1 \mathrm{~h}$. After sintering of the $\beta$-TCP powder at $1,050{ }^{\circ} \mathrm{C}$ for $1 \mathrm{~h}$, a porous $\beta$-TCP block with a mean pore size of $200 \mu \mathrm{m}$ and a porosity of $75 \%$ was obtained. A bimodal pore size distribution in the $\beta$-TCP block with $75 \%$ porosity was observed, where one peak existed in a region of $>100 \mu \mathrm{m}$ and the other peak existed in a region of $<5 \mu \mathrm{m}$. The $\beta$-TCP block with $60 \%$ porosity was synthesized by the same method as the $75 \%$ material, except that the amount of forming agent was changed. The mean compressive strength of $\beta$-TCP blocks with 60 and $75 \%$ porosity was 22 and $3 \mathrm{MPa}$, respectively.

During opening HTO, the opened defect was fixed with a Puddu plate after which the cancellous bone defect was filled with 4 wedge-shaped $\beta$-TCP blocks of $75 \%$ porosity. On the medial side, however, 3 wedge-shaped $\beta$-TCP blocks with $60 \%$ porosity were implanted in front of and at the back of the plate. Eighteen patients received an opening of $10 \mathrm{~mm}$ and 13 patients had an opening of $12.5 \mathrm{~mm}$. The volume of each piece of $\beta$-TCP block with $60 \%$ porosity for a $10 \mathrm{~mm}$ opening was $1.06 \mathrm{~cm}^{3}$ and for a $12.5 \mathrm{~mm}$ opening was $1.39 \mathrm{~cm}^{3}$. Three pieces of $\beta$-TCP were implanted in all cases, but $1 / 3$ of one piece was removed in the case of small knees. To fill the cancellous bone defects, $6-7$ and $7-8 \mathrm{~cm}^{3}$ of $\beta$-TCP blocks with $75 \%$ porosity were used for 10 and $12.5 \mathrm{~mm}$ openings, respectively.

Between 2003 and 2005, opening wedge HTO was performed on 36 patients using a Puddu plate and $\beta$-TCP with 60 and $75 \%$ porosity. Thirty-one patients (22 women and 9 men) with a mean age of 64 years (range 51-77 years) at the time of surgery, were evaluated with a mean follow-up point of 75 months (range 72-78 months).

Exclusion criteria in this study included (1) patients with standing lateral femorotibial angle of more than $184^{\circ}$; (2) patients who had an extension loss of more than $10^{\circ}$; (3) patients who had severe osteoarthritis in the patellofemoral joint; and (4) patients whose BMI was more than $27\left(\mathrm{~kg} / \mathrm{m}^{2}\right)$. After surgery, the knee was protected with a hinged brace for 12 weeks. Partial weight-bearing was allowed at 3-4 weeks, and total weight-bearing was allowed at 5-6 weeks. All patients received follow-up evaluations at regular intervals in our outpatient clinic, and underwent radiographs and $\mathrm{CT}$ examinations at 2 weeks (Fig. 1a) and at 6 years (Fig. 1b). CT images parallel to the osteotomy plane were made and images at the centre were used to evaluate $\beta$-TCP resorption and bone formation. The CT image data were divided into 3 areas by tracing manually on the screen of the computer (Fig. 1-a2, b2). CT attenuation values [in Hounsfield units (HU)] of the area implanted with $\beta$-TCP of $60 \%$ porosity, the area implanted with $\beta$-TCP of $75 \%$ porosity, and hingedcancellous bone were analysed using the imaging software, Osirix. Traces of the $\beta$-TCP blocks were still visible at 6 years post-operatively in some cases, but in most cases, it was hard to define the $\beta$-TCP implanted area. In those cases, CT images at 2 weeks were used to define the $\beta$-TCP implanted area. Circumferential cortical bone of the tibia was excluded from each value of $\beta$-TCP and cancellous bone. 
Fig. 1 CT images of a 64-yearold man showing the centre of the osteotomy plane at 2 weeks $(\mathbf{a 1}, \mathbf{a 2})$ and 6 years $(\mathbf{b 1}, \mathbf{b 2})$. The mean $\mathrm{CT}$ values (HU) of the area implanted with $\beta$-TCP of $60 \%$ porosity (2), the area implanted with $\beta$-TCP of $75 \%$ porosity (3), hinged-cancellous bone (4), and the area with insufficient $\beta$-TCP implantation (5) were, 1,717.3, 1,044.8, 175.1 , and 39.1 , respectively. Six years after surgery, these values were $440.5,162.0,164.3$, and 21.9 , respectively. The area with insufficient $\beta$-TCP implantation (5) showed poor bone formation. (1) indicates the area of the metal plate
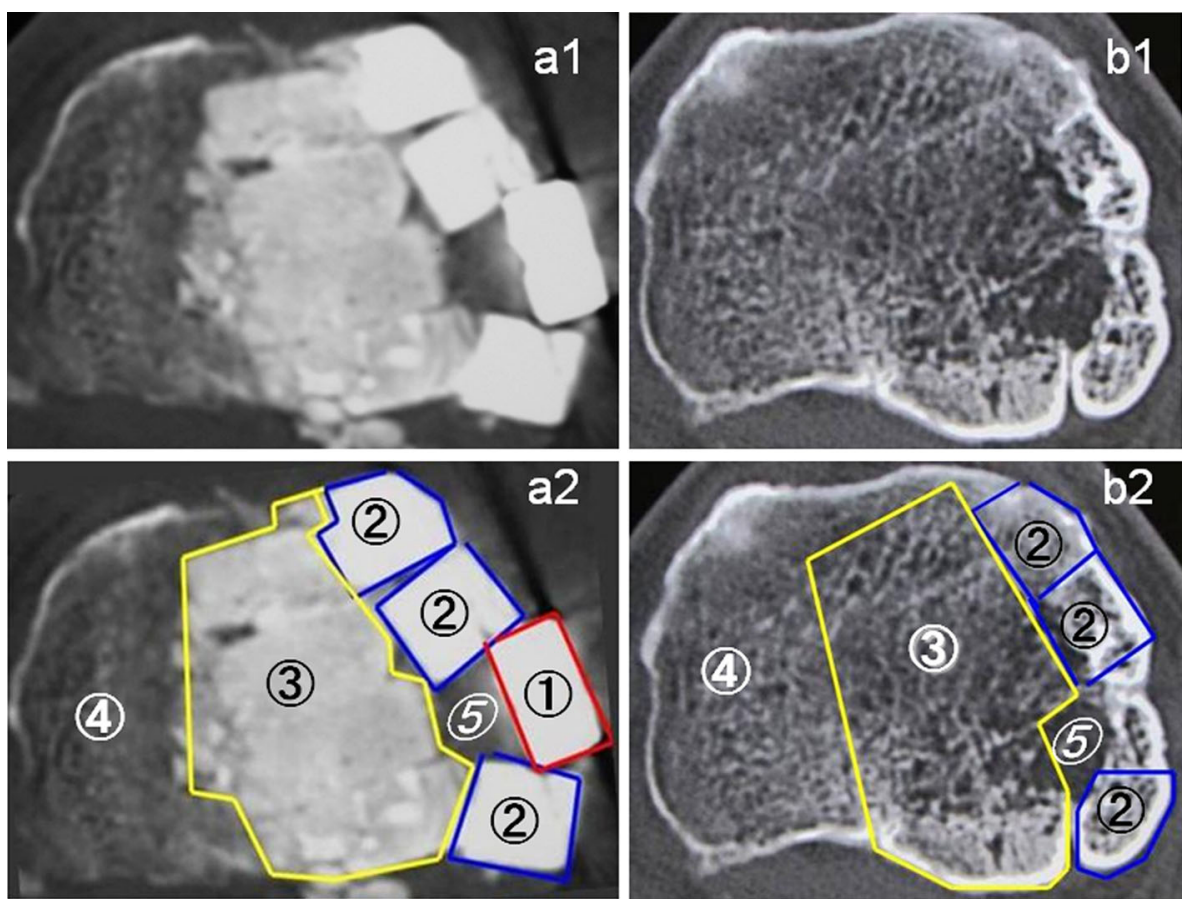

Reproducibility of the radiological evaluating system

The CT images were evaluated independently by two investigators (TT and YK). The two investigators re-evaluated the CT data one more time at 11 months after the first analysis. Inter-observer variability as well as intraobserver variability during the first and second rounds were determined using intraclass correlation coefficient, an appropriate summary statistic for determining the reliability of measurement $[12,20]$.

All patients provided informed consent prior to participation in this study, which was approved by NHO Utsunomiya National hospital ethical committee (ID 15-1).

\section{Statistical analysis}

We used a paired $t$ test to compare CT values of $\beta$-TCP implanted areas and cancellous bone.

A $P$ value of less than 0.05 was regarded as statistically significant.

\section{Results}

The mean preoperative standing lateral femorotibial angle was $181^{\circ}$ (range $177^{\circ}-184^{\circ}$ ), which was corrected to a mean angle of $169^{\circ}$ post-operatively. No correction loss was observed at the final follow-up. Bone formation and $\beta$ TCP resorption were noted in all cases. CT image analysis containing the centre of the osteotomy plane showed that the mean CT value (HU) of the implanted area with $\beta$-TCP

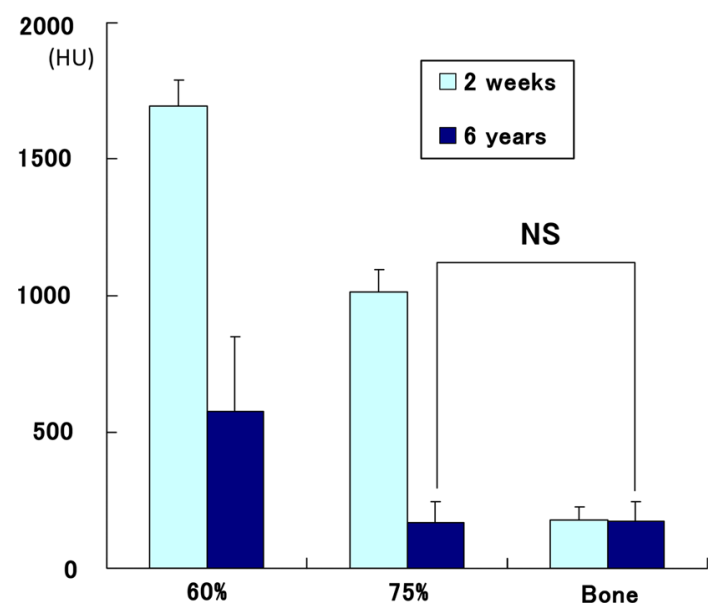

Fig. 2 CT values (HU) obtained from each area of 31 cases at 2 weeks and 6 years. The CT values of $\beta$-TCP with $75 \%$ porosity implanted area at 6 years were not statistically different from those of hinged-cancellous bone, indicating that $\beta$-TCP with $75 \%$ porosity was completely resorbed and replaced by cancellous bone. The labels "60", "75", and "bone" indicate the area implanted with $\beta$-TCP of $60 \%$ porosity, the area implanted with $\beta$-TCP of $75 \%$ porosity, and hinged-cancellous bone, respectively

of $60 \%$ porosity at 2 weeks and 6 years were $1,694.0 \pm 94.2$, and $574.1 \pm 273.5$, respectively. The mean CT value of the implanted area with $\beta$-TCP of $75 \%$ porosity at 2 weeks and 6 years were $1,010.9 \pm 81.1$, and $168.8 \pm 75.1$, respectively. The mean CT value of cancellous bone at 2 weeks and 6 years were $178.0 \pm 45.1$, and $174.9 \pm 69.3$, respectively (Fig. 2). The values with the smallest standard deviation (SD) were for hinged- 
cancellous bone at 2 weeks and values with the largest SD were for areas implanted with $\beta$-TCP of $60 \%$ porosity at 6 years.

Six years after surgery, there was no statistical difference of the CT values between the area implanted with $\beta$-TCP of $75 \%$ porosity and cancellous bone, indicating that the $\beta$-TCP with $75 \%$ porosity had been completely resorbed and replaced by bone. In contrast, the $\mathrm{CT}$ values indicated that approximately $1 / 3$ of the $\beta$-TCP with $60 \%$ porosity remained even 6 years after surgery (Fig. 2).

Significant difference of $\beta$-TCP resorption was not found in the two patients who smoked.

The intraclass correlation coefficients of the $\mathrm{CT}$ values of $60 \%$ porosity $\beta$-TCP, $75 \%$ porosity $\beta$-TCP, and hinged-cancellous bone at 2 weeks and 6 years were determined. The intraclass correlation coefficients of the interobserver measurements for the first and second rounds were $0.67-0.94$ and $0.79-0.96$, respectively. The intraclass correlation coefficients of the intra-observer measurements for the first and second investigators were $0.89-0.96$ and $0.66-0.94$, respectively.

\section{Discussion}

The most important finding of this study was the quantitative evaluation of the $\beta$-TCP resorption and bone formation in opening HTO. There are several reports that evaluate $\beta$-TCP resorption in opening HTO $[1,4,11,16$, 19]. van Hemert et al. [19] developed a radiological rating system to monitor bone healing in opening wedge osteotomies. Remodelling of bone gaps filled with $\beta$-TCP granules or blocks with $70 \%$ porosity was graded into five categories. The results were only analysed by conventional anteroposterior and lateral radiographs, potentially leading to observer variance of radiological measurements. Thus, a specific radiographic rating system is needed. As yet, no radiological rating system using $\mathrm{CT}$ images to monitor bone healing in opening HTO is available. CT values of $60 \%$ and $75 \%$ porosity $\beta$-TCP blocks at the centre of CT images at 2 weeks and 6 years were originally measured; however, CT images at 6 years showed that $\beta$-TCP with $60 \%$ porosity was not uniformly resorbed (Fig. 1). This strongly suggested that measurements focused on a certain area (region of interest) of $\beta$-TCP were inadequate to evaluate $\beta$-TCP resorption. Thus, monitoring of the whole $\beta$-TCP implanted area was necessary. However, it was difficult to analyse CT values of the whole area. We therefore used the imaging software, Osirix, which was developed in 2004 by a team of radiologists from Geneva and UCLA, working on Apple computers, and can be downloaded free of charge. Use of Osirix allowed us to scan the whole area and measure CT values. $\beta$-TCP blocks were still visible at 6 years in some cases, but in most of the cases, it was hard to define the $\beta$-TCP implanted area. In those cases, we referred to CT images taken at 2 weeks to define the $\beta$-TCP-implanted area. The present study showed that there was no statistical difference between the CT values of the area implanted with $\beta$-TCP of $75 \%$ porosity at 6 years and cancellous bone, indicating that $\beta$ TCP with $75 \%$ porosity was completely resorbed and replaced by bone. In contrast, from the $\mathrm{CT}$ values, approximately $1 / 3$ of $\beta$-TCP with $60 \%$ porosity remained even 6 years after surgery. Figure 1 showed that CT values in the area with insufficient $\beta$-TCP implantation was lower than cancellous bone, indicating that poor bone formation occurred in this area. Thus, our evaluation system also proved to be successful at monitoring bone formation.

Meidinger et al. [15] reported on smoking as a risk factor of non-union in opening HTO, but the present study did not show significant difference of $\beta$-TCP resorption in the two patients who smoked.

Some limitations to this study are as follows. First, the CT values of each circumferential cortical bone of the tibia were excluded from each value of $\beta$-TCP and cancellous bone, because it was hard to distinguish newly formed bone from residual $\beta$-TCP. Second, it was hard to obtain completely matched images at 2 weeks and 6 years, even though we tried to measure the centre of the osteotomy plane. Third, the CT images were divided into three areas by tracing manually on the screen of the computer. Although this manual process caused inter- and intraobserver differences, intraclass correlation coefficients analysis showed substantial to almost perfect agreement between the two independent investigators.

The present study showed that $\beta$-TCP with $75 \%$ porosity was completely resorbed and replaced by bone, but $\beta$-TCP with $60 \%$ porosity was only partially resorbed. However, the amount of residual $\beta$-TCP with $60 \%$ porosity was so small that it would not hinder total knee arthroplasty should it be necessary in the future. To promote complete remodeling of $\beta$-TCP, additional stimulations such as growth factors may also be necessary [13].

This system is the first to quantitatively evaluate the residual amount of $\beta$-TCP and bone formation in opening HTO. It will be a useful technique to evaluate $\beta$-TCP resorption and bone formation in any $\beta$-TCP implanted area.

\section{Conclusions}

The aim of this study was to establish a novel evaluation system to monitor bone formation and $\beta$-TCP resorption in opening HTO using the image software, Osirix. The results showed that $\beta$-TCP with $75 \%$ porosity was completely 
resorbed and replaced by bone, but $\beta$-TCP with $60 \%$ porosity was only partially resorbed even 6 years after surgery. The imaging software, Osirix, enabled us to evaluate $\beta$-TCP resorption and bone formation in both opening HTO and other $\beta$-TCP implanted areas.

Conflict of interest The authors declare that they have no conflict of interest.

Open Access This article is distributed under the terms of the Creative Commons Attribution License which permits any use, distribution, and reproduction in any medium, provided the original author(s) and the source are credited.

\section{References}

1. Aryee S, Imhoff AB, Rose T, Tischer T (2008) Do we need synthetic osteotomy augmentation materials for opening-wedge high tibial osteotomy. Biomaterials 29:3497-3502

2. Aurori BF, Weierman RJ, Lowell HA, Nadel CI, Parsons JR (1985) Pseudoarthrosis after spinal fusion for scoliosis. A comparison of autogenic and allogenic bone grafts. Clin Orthop Relat Res 199:153-158

3. Coventry MB (1965) Osteotomy of the upper portion of the tibia for degenerative arthritis of the knee. A preliminary report. J Bone Joint Surg Am 47:984-990

4. Gaasbeek RDA, Toonen HG, van Heerwaarden RJ, Buma P (2005) Mechanism of bone incorporation of beta-TCP bone substitute in open wedge tibial osteotomy in patients. Biomaterials 26:6713-6719

5. Gaasbeek RD, Welsing RT, Verdonschot N, Rijnberg WJ, van Loon CJ, van Kampen A (2005) Accuracy and initial stability of open- and closed-wedge high tibial osteotomy: a cadaveric RSA study. Knee Surg Sports Traumatol Arthrosc 13:689-694

6. Hoogendoorn HA, Renooij W, Akkermans LMA, Visser DDS, Wittebol P (1984) Long-term study of large ceramic implants in dog femora. Clin Orthop Relat Res 187:281-288

7. Jackson JP, Waugh W (1961) Tibial osteotomy for osteoarthritis of the knee. J Bone Joint Surg Br 43:746-751

8. Karcher HL (1997) HIV transmitted by bone graft. BMJ 314:1300

9. Kitsugi T, Yamamoto T, Nakamura T, Kotani S, Kokubo T, Takeuchi H (1993) Four calcium phosphate ceramics as bone substitutes for non-weight-bearing. Biomaterials 14:216-224
10. Koshino T, Murase T, Saito T (2003) Medial opening-wedge high tibia osteotomy with use of porous hydroxyapatite to treat medial compartmental osteoarthritis of the knee. J Bone Joint Surg Am $85: 75-85$

11. Kraal T, Mullender M, de Bruine JHD, Reinhard R, de Gast A, Kuik DJ, van Rosen BJ (2008) Resorbability of rigid beta-tricalcium phosphate wedges in open-wedge high tibial osteotomy: a retrospective radiological study. Knee 15:201-205

12. Kramer MS, Feinstein AR (1981) Clinical biostatistics. The biostatistics of concordance. Clin Pharmacol Ther 29:111-123

13. Marmotti A, Castoldi F, Rossi R, Marenco S, Risso A, Ruella M, Tron A, Borre A, Blonna D, Tarella C (2013) Bone marrowderived cell mobilization by G-CSF to enhance osseointegration of bone substitute in high tibial osteotomy. Knee Surg Sports Traumatol Arthrosc 21:237-248

14. Matsumine A, Myoui A, Kusuzaki K, Araki N, Seto M, Yoshikawa H, Uchida A (2004) Calcium hydroxyapatite ceramic implants in bone tumor surgery. J Bone Joint Surg Br 86:719-725

15. Meidinger G, Imhoff AB, Paul J, Kirchhoff C, Sauerschnig M, Hinterwimmer S (2011) May smokers and overweight patients be treated with a medial open-wedge HTO? Risk factors for nonunion. Knee Surg Sports Traumatol Arthrosc 19:333-339

16. Onodera J, Kondo E, Omizu N, Ueda D, Yagi T, Yasuda K (2013) Beta-tricalcium phosphate shows superior absorption rate and osteoconductivity compared to hydroxyapatite in openwedge high tibial osteotomy. Knee Surg Sports Traumatol Arthrosc. doi:10.1007/s00167-013-2681-y

17. Tanaka T, Chazono M, Komaki H (2006) Clinical application of beta-tricalcium phosphate in human bone defects. Jikeikai Med J 53:23-31

18. Tanaka T, Kumagae Y, Saito M, Chazono M, Komaki H, Kikuchi T, Kitasato S, Marumo K (2008) Bone formation and resorption in patients after implantation of beta-tricalcium phosphate blocks with $60 \%$ and $75 \%$ porosity in opening wedge high tibial osteotomy. J Biomed Mater Res B Appl Biomater 86B:453-459

19. van Hemert WLW, Willems K, Anderson PG, van Heerwaarden RJ, Wymenga AB (2004) Tricalcium phosphate granules or rigid wedge performs in open wedge high tibial osteotomy: a radiological study with a new evaluation system. Knee 11:451-456

20. Wright JG, Treble N, Feinstein AR (1991) Measurement of lower limb alignment using long radiographs. J Bone Joint Surg $\mathrm{Br}$ 73:721-723

21. Zorzi AR, da Silva HGPV, Muszkat C, Marques LC, Cliquet A Jr, de Miranda JB (2010) Opening-wedge high tibial osteotomy with and without bone graft. Artif Organs 35:301-307 